\title{
2016 Annual report from the Italian VATS Group
}

\author{
Piergiorgio Solli*,1, Luca Bertolaccini ${ }^{2}$, Andrea Droghetti ${ }^{3}$, Alessandro Bertani ${ }^{4}$, Alessandro \\ Gonfiotti ${ }^{5}$, Mario Nosotti ${ }^{6}$, Marcello Migliore ${ }^{7}$ \& Roberto Crisci ${ }^{8}$; Italian VATS Group \\ ${ }^{1}$ Department of Thoracic Surgery, Maggiore \& Bellaria Teaching Hospitals, Bologna 40133, Italy \\ ${ }^{2}$ Department of Thoracic Surgery, AUSL Romagna Teaching Hospital, Ravenna 48121, Italy \\ ${ }^{3}$ Department of Thoracic Surgery, ASST Mantova, Mantova 46100, Italy \\ ${ }^{4}$ Department of Thoracic Surgery, IRCCS ISMETT-UPMC, University of Pittsburgh, Palermo 90127, Italy \\ ${ }^{5}$ Department of Thoracic Surgery, University Hospital Careggi, Firenze 50134, Italy \\ ${ }^{6}$ Thoracic Surgery, Fondazione IRCCS Cà Granda Ospedale Maggiore Policlinico, University of Milan, Milan 20122, Italy \\ ${ }^{7}$ Section of Thoracic Surgery, Department of Surgery, Policlinico University Hospital, Catania 95125, Italy \\ ${ }^{8}$ Department of Thoracic Surgery, University of L'Aquila, L'Aquila 67100, Italy \\ * Author for correspondence: piergiorgio.solli@gmail.com
}

This report highlights the results of the Italian video-assisted thoracoscopic surgery (VATS) Group, launched in mid 2013, which now has a website and an established database with over 4000 VATS lobectomy cases recruited from 67 thoracic surgery units across Italy. The year 2016 has been crucial for the following steps: inclusion of a dedicated biostatistician and a 'Survey Analysis \& Data Quality Check'; the First Consensus Meeting with statements consequently adopted as Recommendations for the Italian Thoracic Surgery Society and published in a peer-reviewed journal; two papers published under the logo Italian VATS Group and seven abstracts accepted at annual international meetings (European Society of Thoracic Surgeons, European Association of Cardio-Thoracic Surgeons, European Lung Cancer Conference and European Respiratory Society); the institution of a Master Course on VATS lobectomy; the partnership with AME Publishing Company.

First draft submitted: 14 August 2017; Accepted for publication: 13 October 2017; Published online: 17 April 2018

Keywords: lobectomy $\bullet$ lung cancer $\bullet$ lung resection $\bullet$ multicenter study $\bullet$ study group $\bullet$ thoracoscopic lobectomy - VATS

\section{Brief history of project}

The Italian video-assisted thoracoscopic surgery (VATS) Group project was launched in May 2013 by a dedicated group of enthusiastic Italian thoracic surgeons with the aim to establish a national registry for VATS lobectomy procedures and a related study group.

The idea behind the program was: to promote a standardized surgical technique for VATS lobectomy with the assumption that this will become the accepted standard of care for early stage non-small-cell lung cancer; to assess the existing evidence on VATS lobectomy (cost-effectiveness, safety, oncological outcomes); to endorse tutorial activity and learning across Italy; to eventually improve multi-institutional clinical research on minimally invasive surgery.

After the creation of a Scientific Committee, a website [1] and an online database in the English language, the Registry officially opened for patient's recruitment on 1 January 2014.

\section{Facts \& figures 2017}

Currently, 67 thoracic surgery units across Italy are accredited with the VATS Group: this should be regarded as a remarkable result because each region apart from Calabria is represented within the registry and these counts for $>95 \%$ of all the thoracic surgery units working in the country.

Some of the centers have initially registered with the VATS Group but only subsequently started with data insertion into the database. The picture in mid 2017 is certainly better than previous years because at present 56

Future Medicine 
(A)

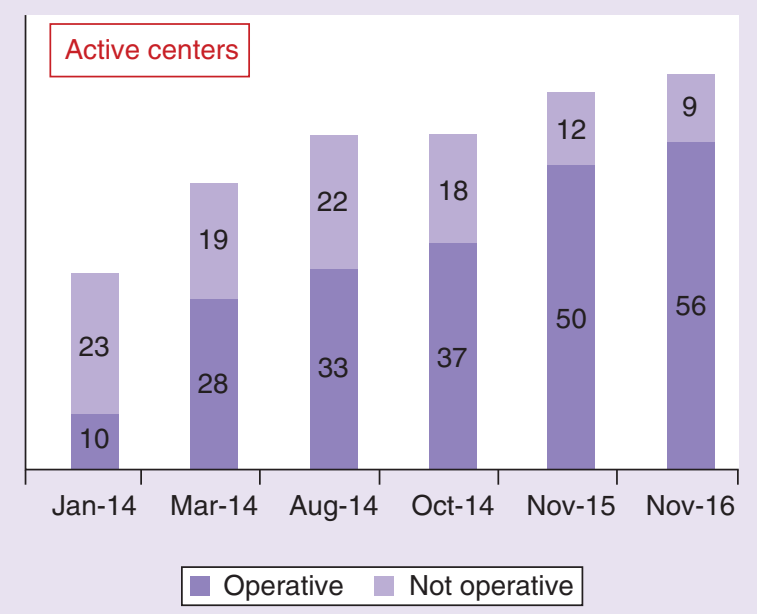

(B)

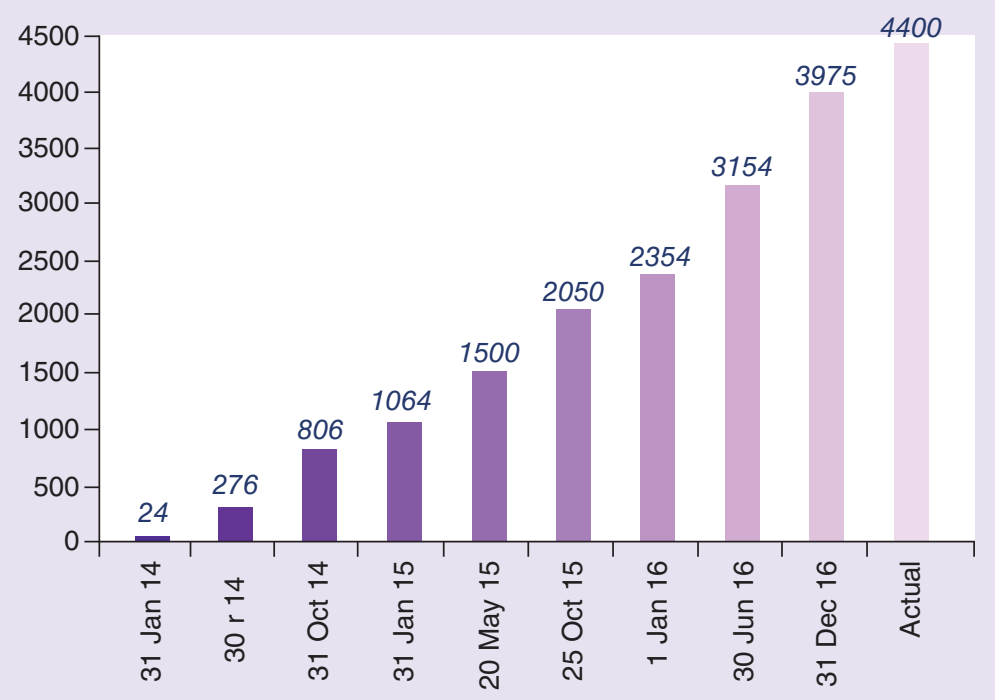

Figure 1. Active centers and number of cases recruited.

Box 1. Surgical technique considered in the database.

- Posterior Edinburgh approach according to Walker [2]

- Lateral approach according to McKenna [3]

- Anterior approach according to D'Amico [4]

- Uniportal approach according to Gonzalez-Rivas [5]

- Totally endoscopic approach according to Gossot [6]

- Anterior approach according to Copenhagen [7]

units are operative while the remaining nine centers are taking part mainly in side activities (scientific meeting, tutorial events) as they are still in the middle of the learning curve phase.

At present (7 May 2017) there are 4400 cases registered, with a similar growth of the activity during the last 2 years. There are ten 'high-volume units', and their recruitment has passed the 100 cases with a pace of almost 50 cases/year, with a uniform distribution between northern and central part of Italy (Figure 1).

Preoperative histology was available for $75 \%$ of patients, mainly through computed tomography-guided fine-needle aspiration biopsy ( $78 \%$ fine-needle aspiration biopsy, $21 \%$ bronchoscopy and endobronchial ultrasound/esophageal ultrasound [EBUS/EUS] 1\%). Preoperative staging included a PET scan study in 96\% of cases with $91 \%$ of clinically $\mathrm{N} 0$-staged cases and $3.8 \%$ of clinical $\mathrm{cN} 1$ disease.

The vast majority were upper lobe tumors (right upper lobectomy the most frequent procedure).

A radical nodal dissection was performed in $74 \%$ of the procedures with an average of 15 lymph nodes harvested, and a median of six nodal station locations explored/case. The remaining $26 \%$ of patients had a nodal sampling, mainly due to surgeon's attitude and center's preference. Mean operative time recorded was $190 \pm 63 \mathrm{~min}$.

The database offers six options in terms of surgical technique [2-7] as reported in Box 1.

The three ports 'Copenhagen' approach is the most broadly adopted technique in Italy ( $74 \%$ of cases), followed by the two-ports technique (11\%). Interestingly the single-port approach, widely diffuse at present especially in the Far East, is increasing and some of the centers are shifting from the multiportal to single-port technique. This is captured in the database with an increase of cases along time: $3 \%$ in $2015,7 \%$ in 2016 and $8 \%$ in 2017 . The other techniques (Edinburgh posterior, McKenna multiport, Gossot totally endoscopic) are less represented in the Registry and rarely utilized in Italy. 
Percentage of conversion remain 9\% (as in 2015), main reasons being vascular injuries (one out of three of the total conversion), calcified nodes on pulmonary artery (one out of five of total conversion), incomplete fissures or other anatomical difficulties (one out of ten of total conversion). No intraoperative or 30-days mortality episodes have been recorded, with an overall morbidity of $19.6 \%$ including prolonged air leak in $7.4 \%$, atrial fibrillation in $6.5 \%$, hemothorax requiring surgical re-exploration in $1.7 \%$ of cases. The average postoperative length of stay was 5.4 days (median 4) with an associated average overall hospitalization of 7.53 days (median 6).

Adenocarcinoma was the most frequent histological subtype (including all variants: in situ adenocarcinoma, minimally invasive adenocarcinoma, invasive adenocarcinoma) followed by squamous cell cancers.

Recurrence of the disease occurred in $5.3 \%$ of the cases and was localized in the lung (44.5\%), locoregional lymph nodes $(29.7 \%)$ or brain $(16.5 \%)$.

\section{Recent developments}

The 2016 has been a crucial year for the activity of the Registry. The inclusion of a dedicated biostatistician into the team leads to the fundamental step of the 2-year 'Survey Analysis \& Data Quality Check of VATS Group Database'.

The survey process included a short easy-to-handle questionnaire distributed via the internet to all the centers. We could recognize that the penetrance of VATS lobectomy (VATS Index Score; i.e., the number of lobectomies performed via a minimally invasive approach out of all the lobectomies carried out in a single center) is currently 49.6\%, in line with other countries in Europe (the Netherlands and Denmark 50 and 52\%, respectively). Each center has a median of two thoracic surgeons dedicated to VATS lobectomy, and these are senior consultants (79\% with $>10$ years of independent clinical practice after completion of the residency). They developed their skill in minimally invasive surgery through attendance of focused VATS lobectomy interactive courses in $50 \%$ of cases or residential courses in $22 \%$ of cases, both followed by proctoring.

Through the survey the participants had the chance to suggest and submit innovative ideas or adjuncts/amendments to the currently used database; while 73\% declared that were satisfied with the database as it is, $21 \%$ made suggestions, and some of these were subsequently adopted (new data box on lymph nodes harvesting, pathology and staging).

This year the registry also underwent to the Data Quality Check under the surveillance of Quality Committee, the biostatistician and the engineers involved in construction and maintenance of the online database. It was also agreed that data check would be executed biannually. Evaluation steps were: data quality analysis and database document compilation, data quality criteria, data quality characteristics (accuracy, timeliness, comparability, usability, relevance), data quality dimensions and overall evaluation. Data were not acceptable in 181/3549 (5.1\%). Most of these errors were related to the accuracy of data inputs, the follow-up data and lacking patient 'validation' (only cases with the complete set of information are considered as part of the registry; the absence even of few data generates a sheet on a particular patient that is not regarded as completed and is not included in the overall calculation until the case is integrated with the missing information and could be eventually 'validated'). In ten centers with almost 100 VATS, lobectomies recorded in the database demonstrated strong characteristics of comprehensiveness, integration, standardization, equivalency, comparability and adaptability [8].

On 29-30 October 2015, the First consensus meeting on VATS lobectomy for non-small-cell lung cancer took place in Giulianova (Pescara, Italy). The Scientific Board of the VATS Lobectomy Group identified the Consensus Meeting as an appropriate tool for a national debate, and the consensus conference was organized following indications of the Italian Department of Health: a panel of experts reviewed the literature, the Jury Board revised the experts' reports and the national conference discussed and voted on statements. Eighty-six senior Italian thoracic surgeons attended the meeting, 33 topics were discussed with a focus on indications, surgical strategy, perioperative management and training. The consensus was reached on 24 statements that were consequently adopted as recommendations for the Italian Thoracic Surgery Society that were published in a peer-reviewed journal in 2016 [9].

\section{Scientific activity, papers \& abstracts prepared under the logo Italian VATS Group}

2016/2017 has been an outstanding year for the scientific activity of the group.

Two papers have been published [9,10]. Seven abstracts have been accepted at the two European Conferences of Thoracic Surgery (European Society of Thoracic Surgeons [ESTS] and European Association of Cardio-Thoracic Surgeons), at the European Lung Cancer Conference and at the European Respiratory Society (ERS) and will be 
Table 1. List of 2016 abstracts \& papers.

\begin{tabular}{|c|c|}
\hline Abstracts \& papers & Presented/published \\
\hline $\begin{array}{l}\text { Nodal management and upstaging: } \\
\text { initial results from the Italian VATS national database }\end{array}$ & ESTS 2016 Annual Meeting \\
\hline $\begin{array}{l}\text { Safety \& effectiveness of nodal dissection during VATS lobectomy: } \\
\text { data from the Italian VATS registry }\end{array}$ & EACTS 2016 Annual Meeting \\
\hline $\begin{array}{l}\text { Standardized uptake value and radiological density attenuation as predictive } \\
\text { value and prognostic factors for solitary pulmonary nodule }\end{array}$ & The Journal of Thoracic Disease submitted \\
\hline Vascular injury during VATS lobectomy: data from the Italian VATS registry & $\begin{array}{l}\text { ESTS } 2017 \text { Annual Meeting } \\
\text { Brompton Prize best oral presentation }\end{array}$ \\
\hline Learning curve in VATS lobectomy: the Italian VATS group experience & $\begin{array}{l}\text { ESTS } 2017 \text { Annual Meeting } \\
\text { Best Poster Prize }\end{array}$ \\
\hline $\begin{array}{l}\text { VATS lobectomy for non-small-cell lung cancer after induction chemotherapy: } \\
\text { a propensity score-matched analysis }\end{array}$ & ELCC Annual Meeting 2017 [11] \\
\hline $\begin{array}{l}\text { Preliminary data about quality check evaluation of the Italian VATS Group } \\
\text { database }\end{array}$ & ERS Congress 2017 [8] \\
\hline
\end{tabular}

subsequently submitted as manuscripts for potential publication in their respective journals. Of note, two of these abstracts have been selected during the ESTS annual meeting for the Brompton Prize best oral presentation and best poster, respectively. Table 1 includes a list with details.

During 2016 the VATS Group has identified the fast track in thoracic surgery as a potentially interesting topic for the future and decided to focus on Enhanced Recovery After Surgery. A dedicated subcommittee has been created with the ultimate goal to study this aspect within minimally invasive thoracic surgery in Italy.

\section{Networking, teaching activity for junior doctors, future developments}

The Italian VATS Group has officially purposed to the ESTS to create a unique database on VATS lobectomy pooling all data from both registries together. This has been considered crucial for future studies aiming to create one of the largest patient's samples from all accredited centers over Europe. This process would potentially require a preliminary data auditing through Minimally Invasive Thoracic Interest Group (MITIG), the branch of ESTS dedicated to this topic.

During 2016 the University of L'Aquila with the endorsement of the Italian VATS Group launched the first Master course on VATS lobectomy in Italy. Six students per year will be qualified across different thoracic surgery units in Italy over a period of 18 months. The program will include oral teaching sessions, cadaveric and animal lab training and few weeks of attendance in high-volume units in Italy or abroad.

Eventually, an agreement of strategic partnership with AME Publishing Company has been officially signed [12]. The partnership is another significant move by the VATS Group and will also involve the Italian Society of Thoracic Surgery. Established in July 2009, AME Publishing Company has been focusing on publishing medical journals and books, as well as developing an integrated academic platform. AME stands for 'Academic Made Easy, Excellent and Enthusiastic'. In particular, AME Publishing Company provides three journals focusing on Surgery/Thoracic Surgery (Journal of Visualized Surgery [JOVS], Video-Assisted Thoracic Surgery [VATS] Journal and Journal of Thoracic Disease [JTDJ). For more information about AME and AME journals, please visit the website at [13].

\footnotetext{
Acknowledgements

Italian VATS Group collaborators: Carlo Curcio (Monaldi Hospital, Napoli); Dario Amore (Monaldi Hospital, Napoli); Giuseppe Marulli (University of Padova); Samuele Nicotra (University of Padova); Andrea De Negri (San Martino Hospital, Genova); Paola Maineri (San Martino Hospital, Genova); Gaetano di Rienzo (Vito Fazzi Hospital, Lecce); Camillo Lopez (Vito Fazzi Hospital, Lecce); Angelo Morelli (S Maria delle Misericordia Hospital, Udine); Francesco Londero (S Maria delle Misericordia Hospital, Udine); Lorenzo Spaggiari (IEO Hospital, Milano); Roberto Gasparri (IEO Hospital, Milano); Guido Baietto (Maggiore della Carità Hospital, Novara); Caterina Casadio (Maggiore della Carità Hospital, Novara); Maurizio Infante (Borgo Trento Hospital, Verona); Cristiano Benato (Borgo Trento Hospital, Verona); Marco Alloisio (IRCCS Humanitas, Milano); Edoardo Bottoni (IRCCS Humanitas, Milano); Giuseppe Cardillo (Forlanini Hospital, Roma); Francesco Carleo (Forlanini Hospital, Roma); Franco Stella (S Orsola Hospital, Bologna); Giampiero Dolci (S Orsola Hospital, Bologna); Francesco Puma (University of Perugia); Damiano Vinci (University of Perugia); Giorgio Cavallesco (University of Ferrara); Pio Maniscalco (University of Ferrara); Luca Ampollini (University of Parma); Paolo Carbognani (University
} 
of Parma); Alberto Terzi (Negrar Hospital, Verona); Andrea Viti (Negrar Hospital, Verona); Giampiero Negri (S Raffaele Hospital, Milano); Alessandro Bandiera (S Raffaele Hospital, Milano); Reinhold Perkmann (Bolzano Hospital, Bolzano); Francesco Zaraca (Bolzano Hospital, Bolzano); Claudio Andretti (S Andrea Hospital, Roma); Camilla Poggi (S Andrea Hospital, Roma); Felice Mucilli (S Maria Annunziata Hospital, Chieti); Pierpaolo Camplese (S Maria Annunziata Hospital, Chieti); Luca Luzzi (University of Siena); Marco Ghisalberti (University of Siena); Andrea Imperatori (University of Varese); Nicola Rotolo (University of Varese); Luigi Bortolotti (Humanitas Gavazzeni Hospital, Bergamo); Giovanna Rizzardi (Humanitas Gavazzeni Hospital, Bergamo); Massimo Torre (Niguarda Hospital, Milano); Alessandro Rinaldo (Niguarda Hospital, Milano); Armando Sabbatini (Ospedali Riuniti, Ancona); Majed Refai (Ospedali Riuniti, Ancona); Mauro Roberto Benvenuti (Spedali Civili, Brescia); Diego Benetti (Spedali Civili, Brescia); Alessandro Stefani (Ospedale Policlinico, Modena); Pamela Natali (Ospedale Policlinico, Modena); Paolo Lausi (Ospedale Molinette, Torino); Francesco Guerrera (Ospedale Molinette, Torino).

Financial \& competing interests disclosure

The authors have no relevant affiliations or financial involvement with any organization or entity with a financial interest in or financial conflict with the subject matter or materials discussed in the manuscript. This includes employment, consultancies, honoraria, stock ownership or options, expert testimony, grants or patents received or pending, or royalties.

No writing assistance was utilized in the production of this manuscript.

\section{Summary points}

- The Italian video-assisted thoracic surgery (VATS) Group was created in 2013 by the Italian thoracic surgeons community with the aim to establish a national registry for VATS lobectomy procedures and a related study group.

- Main goals are: to promote a standardized surgical technique for VATS lobectomy with the assumption that this will become the accepted standard of care for early stage non-small-cell lung cancer; to assess the existing evidence on VATS lobectomy (cost-effectiveness, safety, oncological outcomes); to endorse tutorial activity and learning across Italy; to improve multi-institutional clinical research on minimally invasive surgery; to have an online database and a dedicated website [14]

- Currently, 67 thoracic surgery units across Italy are accredited with the VATS Group (95\% of all the units of the country). At present there are over 4400 cases registered and 10 'high-volume units' (recruitment has passed the 100 cases with a pace of almost 50 cases/year).

- The three-ports 'Copenhagen' approach is the most broadly adopted technique in Italy (74\% of cases), followed by the two-ports technique (11\%). The single-port approach, widely diffuse at present especially in the Far East, is increasing and some of the centers are shifting from the multiportal to single-port technique.

- Percentage of conversion remains $9 \%$ (as in 2015), main reasons being vascular injuries (one out of three of the total conversion). No intraoperative or 30-days mortality episodes have been recorded, with an overall morbidity of $19.6 \%$ (main represented complication prolonged air leak in $7.4 \%$ ).

- Recent developments include a survey process, the institution of a quality data check, the data auditing process introductory to application for European Society of Thoracic Surgeons database accreditation, the institution of a Master on VATS lobectomy, the first consensus meeting.

\section{References}

1. VATS Group (2017). http://vatsgroup.org/sito/index.php

2. Richards JM, Dunning J, Oparka J, Carnochan FM, Walker WS. Video-assisted thoracoscopic lobectomy: the Edinburgh posterior approach. Ann. Cardiothorac. Surg. 1(1), 61-69 (2012).

3. McKenna RJ, Mahtabifard A, Swanson SJ. Atlas of Minimally Invasive Thoracic Surgery (VATS). Saunders, USA (2010).

4. Burfeind WR, D’Amico TA. Thoracoscopic lobectomy. Operative Tech. Thoracic Cardiovasc. Surg. 9(2), 98-114 (2004).

5. Gonzalez-Rivas D, Paradela M, Fernandez R et al. Uniportal video-assisted thoracoscopic lobectomy: two years of experience. Ann. Thorac. Surg. 95(2), 426-432 (2013).

6. Gossot D. Atlas of Endoscopic Major Pulmonary Resections. Springer-Verlag, Paris, France (2010).

7. Hansen HJ, Petersen RH. Video-assisted thoracoscopic lobectomy using a standardized three-port anterior approach - the Copenhagen experience. Ann. Cardiothorac. Surg. 1(1), 70-76 (2012).

8. Bertolaccini L, Bertani A, Gonfiotti A et al. Preliminary data about quality check evaluation of the Italian VATS Group database. Eur. Respir. J. 50, OA3222 (2017).

9. Nosotti M, Droghetti A, Luzzi L, Solli P, Crisci R, the Italian VATS Group. First Italian consensus conference on VATS lobectomy for NSCLC. Tumori 103(2), 124-135 (2017). 
10. Bertani A, Gonfiotti A, Nosotti $\mathrm{M}$ et al. Nodal management and upstaging of disease: initial results from the Italian VATS Lobectomy Registry. J. Thorac. Dis. 9(7), 2061-2070 (2017).

11. Bertolaccini L, Pardolesi A, Argnani D et al. Video-Assisted thoracic surgery (VATS) lobectomy for non-small cell lung cancer after induction chemotherapy: a propensity score-matched analysis on behalf of the Italian VATS Group. Ann. Oncol. 28, ii24-ii27 (2017).

12. Strategic partnership agreement between AME Publishing Company and Italian Society of Thoracic Surgery (SICT) is signed! (2018). http://jtd.amegroups.com/announcement/view/161

13. AME Publishing Company. www.amegroups.com

14. VATS Group. www.vatsgroup.org 